\title{
Guanosine nucleotides inhibit different syndromes of PTHrP excess caused by human cancers in vivo

\author{
Wolfgang E. Gallwitz, ${ }^{1}$ Theresa A. Guise, ${ }^{2}$ and Gregory R. Mundy ${ }^{1,2}$ \\ ${ }^{1}$ OsteoScreen Ltd., San Antonio, Texas, USA \\ ${ }^{2}$ Department of Molecular Medicine, University of Texas Health Science Center at San Antonio, San Antonio, Texas, USA
}

\begin{abstract}
There are two well-described syndromes caused by tumor production of parathyroid hormone-related peptide (PTHrP), namely osteolytic bone disease associated with breast cancer and humoral hypercalcemia of malignancy (HHM) that occurs with or without bone metastasis. Both syndromes have been shown experimentally to be inhibited by neutralizing antibodies to PTHrP. In a search for small-molecule inhibitors of PTHrP production or effects, we have identified guanine-nucleotide analogs as compounds that inhibit PTHrP expression by human tumor cells associated with these syndromes. We show in nude athymic murine models that these compounds reduce PTHrP-mediated osteolytic lesions associated with metastatic human breast-cancer cells as well as the degree of hypercalcemia caused by excessive PTHrP production by a squamous-cell carcinoma of the lung. These results suggest that the PTHrP gene promoter may be a suitable target for treating the skeletal effects of malignancy.
\end{abstract}

J. Clin. Invest. 110:1559-1572 (2002). doi:10.1172/JCI200211936.

\section{Introduction}

Tumors affect the skeleton by causing either metastatic bone disease or humoral hypercalcemia of malignancy (HHM). Recent evidence indicates that in both situations, the major mediator is the tumor peptide parathyroid hormone-related peptide (PTHrP). In metastatic osteolytic bone disease without hypercalcemia, neutralizing antibodies to PTHrP inhibit localized osteolytic destruction of bone in nude mice inoculated with human breast-cancer cells that have metastasized to the marrow cavity (1). In HHM, there is convincing evidence that treatment with neutralizing antibodies to PTHrP mitigates the biological effects of PTHrP and lowers serum calcium concentrations in nude mice bearing human squamous-cell carcinomas $(2,3)$.

Although hypercalcemia has been more extensively studied, osteolytic bone metastasis is both a catastrophic and more common complication of human cancers, most notably breast and lung cancer. Approximately 200,000 Americans die of these cancers each year, and the vast majority have bone metastases, which cause considerable suffering and morbidity, including intractable pain, pathological fracture, hypercalcemia, and nerve compression syndromes $(4,5)$. A large pro-

Received for publication December 5, 2000, and accepted in revised form September 17, 2002.

Address correspondence to: W.E. Gallwitz, OsteoScreen Ltd., 2040 Babcock Road, Suite 201, San Antonio, Texas 78229, USA. Phone: (210) 614-0770 ext. 228; Fax: (210) 614-0797;

E-mail: gallwitz@osteoscreen.com.

Conflict of interest: The authors have declared that no conflict of interest exists.

Nonstandard abbreviations used: parathyroid hormone-related peptide (PTHrP); humoral hypercalcemia of malignancy (HHM). portion of the tumor burden may be found in the skeleton in patients with advanced disease.

Bisphosphonates, which have been approved for use in HHM for over a decade, are now also available for treatment of osteolysis associated with breast cancer and have proved very successful. Treatment with these compounds has led to a decrease by approximately $50 \%$ in skeleton-related events associated with metastatic breast cancer $(6,7)$. These events include episodes of intractable pain, the need for analgesics, radiation therapy, the incidence of fracture, and hypercalcemia. Bisphosphonates, however, have had another beneficial effect - they have been associated with a decrease in tumor burden. This effect has been shown in both clinical studies (8) and experiments in animals (9). The mechanism responsible has been debated (10). Although bisphosphonates may cause an increase in tumor-cell apoptosis in vivo (11), the mechanism may be indirect.

In this study, we have evaluated the effects of compounds that reduce the secretion of PTHrP in vivo in animal models of tumor-associated osteolysis and HHM. In the model of osteolysis, human breast-cancer cells inoculated systemically seed to bone and produce PTHrP locally, which in turn leads to osteolytic bone lesions without hypercalcemia. In the model of HHM, human squamous carcinoma cells inoculated subcutaneously cause hypercalcemia due to massive production of PTHrP without metastasis (12). We found two closely related analogs of guanine that inhibit secretion of PTHrP by breast-cancer and lung-cancer cells both in vitro and in vivo and that reduce the size and number of osteolytic bone lesions and the degree of HHM in these two in vivo models of PTHrP excess. 


\section{Methods}

Cells. The human breast-cancer cell line MDA-MB-231

(13), The human breast-cancer cell line stably transfected with the luciferase reporter gene MDA231F9AD/Luc (14), the human lung-cancer cell line RWGT2 (1), and the human osteoblast-like cell line MG63 were cultured in DMEM (Mediatech, Herndon, Virginia, USA) containing 10\% FCS (HyClone Laboratories, Logan, Utah, USA), $1 \%$ penicillin/streptomycin, and $1 \%$ L-glutamine (Mediatech). The mouse osteoblast clonal cell line 2T3 (15) was cultured in $\alpha$-MEM (Mediatech) containing 10\% FCS (HyClone Laboratories), $1 \%$ penicillin/streptomycin, and $1 \%$ L-glutamine (Mediatech). Cells were cultured in a $37^{\circ} \mathrm{C}$ atmosphere of $5 \% \mathrm{CO}_{2}$ and $95 \% \mathrm{O}_{2}$.

The human breast-cancer cell line MCF-7 (16) was cultured in Iscove's Modified Dulbecco's Medium (IMDM; Mediatech) containing 10\% FCS (HyClone Laboratories), $1 \%$ penicillin/streptomycin, and L-glutamine (Mediatech). The human breast-cancer cell line ZR-75 (17) was cultured in RPMI (Mediatech) containing 10\% FCS (HyClone Laboratories), 1\% penicillin/streptomycin, and L-glutamine (Mediatech). All cells were cultured in a $37^{\circ} \mathrm{C}$ atmosphere of $5 \% \mathrm{CO}_{2}$ and $95 \% \mathrm{O}_{2}$.

To test the effects of compounds on PTHrP secretion by MDA-MB-231 or RWGT2 cells, $10^{4}$ cells $/ \mathrm{ml}$ were plated onto 48-well plates (Costar, Cambridge, Massachusetts, USA). When the cells were $90 \%$ confluent, they were washed with PBS, and compounds containing $250 \mu \mathrm{l}$ serum-free DMEM/0.1\% BSA (SigmaAldrich, St. Louis, Missouri, USA) were added. Compounds were tested at $0,0.001,0.01,0.1,1$, and $10 \mu \mathrm{M}$. Conditioned media were collected after 48 hours and stored at $-70^{\circ} \mathrm{C}$ for measurement of PTHrP concentrations, and the cells in each well were counted to correct the PTHrP concentration of the conditioned media. To prepare the MDA-MB-231 and RWGT2 cells for right-flank intramuscular injection, cells were trypsinized, washed twice with PBS, and resuspended in PBS to a final concentration of $10^{7}$ cells $/ 100 \mu$ l. To prepare the MDA-MB-231 or MDA-231F9AD/Luc cells for injection in the left cardiac ventricle, cells were trypsinized, washed twice with PBS, and resuspended in PBS to a final concentration of $10^{5}$ cells $/ 100 \mu$ l.

Animals. Animal protocols were approved by the Institutional Animal Care and Use Committee at the University of Texas Health Science Center at San Antonio and were conducted in accordance with the NIH Guide for the Care and Use of Laboratory Animals. Athymic nude mice (Harlen Industries, Houston, Texas, USA), 4-6 weeks of age, were housed in a laminar flow isolator hood with a 12 hour light/ 12 hour dark cycle. Water and autoclaved mouse chow (Ralston-Purina, St. Louis, Missouri, USA) were provided ad libitum.

Whole-blood samples for determination of blood ionized-calcium concentrations were obtained by retroorbital puncture. Blood samples for measurement of PTHrP concentrations were similarly obtained and collected on ice into pediatric vacutainer tubes containing
EDTA (Becton Dickinson, Rutherford, New Jersey, USA) and $400 \mathrm{KIU} / \mathrm{ml}$ of aprotinin (Sigma-Aldrich).

Oligonucleotides. Oligonucleotides were synthesized on an Oligo 1000M automated synthesizer (Beckman, Fullerton, California, USA). The primer sets used were $\beta 2$-microglobulin sense, $5^{\prime}$-CCAGCAGAGAATGGAAAGTC$3^{\prime}$, and antisense, $5^{\prime}$-GATGCTGCTTACATGTCTCG-3'; and PTHrP sense, 5'-TCCATCCAAGATTTACGGCG-3', and antisense, $5^{\prime}$-CCTGCAATATGT CCTTGGAAGG-3'.

Bone metastasis. To investigate whether compounds inhibit bone metastasis, female athymic nude mice (five mice per group) were inoculated with MDA-MB231 tumor-cell suspensions $\left(10^{5}\right.$ cells $/ 100 \mu$ l of PBS) in the left cardiac ventricle on day 0 . Administration of the compound was begun the following day or when lesions became evident. On days 14, 21, and 28, radiographs were obtained and analyzed as described below. On day 28, all bones and soft tissues were fixed in formalin for histological analysis. Necropsy was performed on all mice, and those with tumor in the chest were excluded from analysis, because this indicated that the tumor inoculum did not properly enter the left cardiac ventricle.

To investigate whether compounds inhibit bone metastasis independently of the PTHrP promoter, on day 0 we inoculated female athymic nude mice (five mice per group) in the left cardiac ventricle with MDA-MB-231 tumor-cell suspensions $\left(10^{5}\right.$ cells/100 $\mu \mathrm{l}$ PBS) stably transfected with the cDNA for human Prepro-PTHrP by the cytomegalovirus promoter. This tumor-cell line expresses 100 pM PTHrP/24 hours, as compared with the wild-type MDA-MB-231 cell line, which expresses 8.4 pM PTHrP/24 hours. Administration of the compound was begun the following day. On days 14 and 21, radiographs were obtained and analyzed as described below. On day 21, all bones and soft tissues were fixed in formalin for histological analysis as described below.

Local tumor growth. To investigate whether compounds inhibit tumor growth, MDA-MB-231 tumorcell suspensions $\left(10^{7}\right.$ cells $/ 100 \mu \mathrm{l}$ PBS) were injected into the right flank of female athymic nude mice. Tumor volume was measured with calipers and calculated by the following formula of an ovoid: tumor volume $=(4 / 3) \pi \times \mathrm{L} / 2(\mathrm{~W} / 2)^{2}$, where $\mathrm{L}$ equals midaxis length and $\mathrm{W}$ equals midaxis width.

Tumor burden. To investigate how compounds affect tumor burden, female athymic nude mice (five mice per group) were inoculated with MDA-231F9AD/Luc tumor-cell suspensions $\left(10^{5}\right.$ cells $/ 100 \mu \mathrm{l}$ PBS) in the left cardiac ventricle on day 0 . Administration of the compound was begun the following day. On day 28, all hind-limb tibias and adrenal glands were processed to measure luciferase activity as described below.

Hypercalcemia. To investigate whether compounds inhibit hypercalcemia, male athymic nude mice (five mice per group) were inoculated with RWGT2 tumorcell suspensions $\left(10^{7}\right.$ cells $\left./ 100 \mu \mathrm{l} \mathrm{PBS}\right)$ in the right flank on day 0 . Administration of the compound was 
begun the following day (prevention) or when hypercalcemia became evident (treatment). On days 7, 11, and 14, whole-blood samples were tested for ionizedcalcium ion PTHrP concentrations to assess the effectiveness of compounds as described below.

Measurement of whole-blood ionized-calcium concentrations. Whole-blood ionized-calcium concentrations were measured with the use of a Ciba Corning 634 ISE $\mathrm{Ca}^{++} / \mathrm{pH}$ analyzer (Corning Medical and Scientific, Medfield, Massachusetts, USA) and adjusted to $\mathrm{pH}$ 7.4. Samples were run in duplicate, and the mean value was recorded.

$\mathrm{PTHrP}$ assay. Immunoreactive PTHrP concentrations were measured in the conditioned media of compound-treated MDA-MB-231 cells with the use of a two-site immunoradiometric assay kit (Nichols Institute, San Juan Capistrano, California, USA). PTHrP concentrations were determined from a standard curve generated by adding recombinant PTHrP (1-86) to unconditioned media.

Radiographs and measurement of osteolytic-lesion area. To follow the development of lesions, mice were anesthetized, placed in a prone position against the films (X-OMAT AR; Eastman Kodak Co., Rochester, New York, USA), and exposed at $35 \mathrm{kVp}$ for 6 seconds with the use of a Faxitron radiographic inspection unit (model 43855A; Faxitron X-ray Corp., Buffalo Grove, Illinois). Films were developed with the use of an RP X-OMAT processor (model M6B; Eastman Kodak Co.). The area of osteolytic bone metastases was calculated with the use of a computerized image-analysis system. Quantification of lesion area was performed with image-analysis software (JAVA, Jandel Video Analysis; Jandel Scientific, San Rafael, California, USA).

Bone histology and histomorphometry. Forelimb and hindlimb long bones were removed from mice at sacrifice, fixed in $10 \%$ buffered formalin, decalcified in $14 \%$ EDTA, and embedded in paraffin wax. Sections were cut, placed on poly-L-lysine-coated glass slides, and stained with hematoxylin, eosin, orange G, and phloxine. The following variables were measured in representative midsections of tibias and femurs to assess tumor involvement: total bone area, total tumor area, and osteoclast number expressed per millimeter of tumor-bone interface. Histomorphometric analysis was performed on an OsteoMeasure System (Osteometrics, Atlanta, Georgia, USA).

Luciferase activity. To evaluate tumor burden at sacrifice, the bone marrow of the hindlimb tibia was flushed with PBS into Eppendorf tubes. Samples were centrifuged at room temperature at $1,000 \mathrm{~g}$ for 5 minutes, and the supernatant was removed. Pellets were resuspended in $100 \mu \mathrm{l}$ of $1 \times$ luciferase reporter lysis buffer (Promega, Madison, Wisconsin, USA). Adrenal glands were dissected and placed in $100 \mu \mathrm{l}$ of $1 \times$ luciferase reporter lysis buffer. After a 15 minute incubation at room temperature, sample tubes were vortexed and spun down at $4^{\circ} \mathrm{C}$ at $10,000 \mathrm{~g}$ for 15 minutes, and the supernatant was harvested and stored at $-70^{\circ} \mathrm{C}$.
Luciferase activity was measured with the Luciferase Assay System (Promega), and protein concentrations were measured with the Bio-Rad DC Protein Assay (BioRad Laboratories, Hercules, California, USA).

PTHrP promoter activity assay. To assess the inhibitory effects of compounds on PTHrP promoter activity, we used the $4.3 \mathrm{~kb} 5^{\prime}$-flanking region $(-4335 /+3)$ and the $1.1 \mathrm{~kb} 5$ '-flanking region $(-1120 /+3)$ of the human PTHrP gene. The fragments were ligated into the multiple cloning site of the pGL3-Basic firefly luciferase reporter vector (Promega). The constructs were stably transfected into MDA-MB-231 cells, and the cells were cloned by limiting dilution. The construct with the 1.1 $\mathrm{kb} 5^{\prime}$-flanking region responded in the same manner as the construct with the $4.3 \mathrm{~kb} 5^{\prime}$-flanking region to treatment with $2.5 \mathrm{mM}$ dexamethasone, the control used in the assay. The activity assays for the PTHrP 5'flanking region were run in 96-well tissue-culture plates (Becton Dickinson, Franklin Lakes, New Jersey, USA). A total of $5 \times 10^{3}$ cells in DMEM $/ 10 \%$ FCS were added to each well and allowed to incubate at $37^{\circ} \mathrm{C}$ in $5 \% \mathrm{CO}_{2}$ and $95 \% \mathrm{O}_{2}$ for 24 hours. The MDA-MB-231 cells containing the PTHrP/luciferase constructs were washed twice in PBS, and treatment with compounds in DMEM $/ 2.5 \%$ FCS was begun. Twenty-four hours later, firefly luciferase activity was assayed with the Luciferase Assay System (Promega), and protein concentrations were measured with the Bio-Rad DC Protein Assay (Bio-Rad Laboratories). All compounds that were inhibitory at concentrations of $1 \mu \mathrm{M}$ or less in the PTHrP promoter activity assay (i.e., inhibition greater than that caused by $2.5 \mathrm{mM}$ dexamethasone) were tested for cytotoxicity by Trypan blue exclusion. Any compounds that were cytotoxic were excluded from further analysis. To demonstrate the specificity of the compounds for the PTHrP promoter, we tested the effects of compounds on other promoters unrelated to PTHrP that were operatively linked to the firefly luciferase gene. These included the cAMP response element/serum response element (CRE/SRE), the $769 \mathrm{bp}$ cytomegalovirus enhancer and immediate-early (CMV) promoter, the SV40 promoter (pGL3-Promoter Vector, Promega), the mouse $(-2712 /+165)$ bone morphogenic protein 2 (BMP-2) promoter, the mouse $(-2372 /+258)$ BMP-4 promoter, and the human $(-1243 /+6)$ interleukin $6(\mathrm{IL}-6)$ promoter. Any compounds that demonstrated inhibition of firefly luciferase activity coupled to the aforementioned promoters were excluded from further analysis.

Several random libraries of diverse chemical compounds comprising aromatics; nitrogen, oxygen, and sulfur heterocycles; terpenoids; quaternaries; mesomeric betaines; quinines; polypeptides; tropanes; alkyl, heteroalyl, and aralkyl piperidines; hetero- and aralkylphosphonates; sulfonamides; quarternary amines; and marketed generic drugs totaling 9,600 compounds were examined at concentrations of $10 \mu \mathrm{M}$. These compounds were obtained from MicroSource (New Haven, Connecticut, USA). 


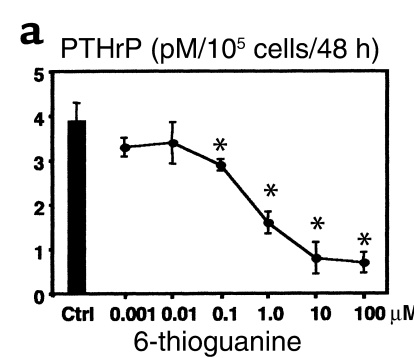

b
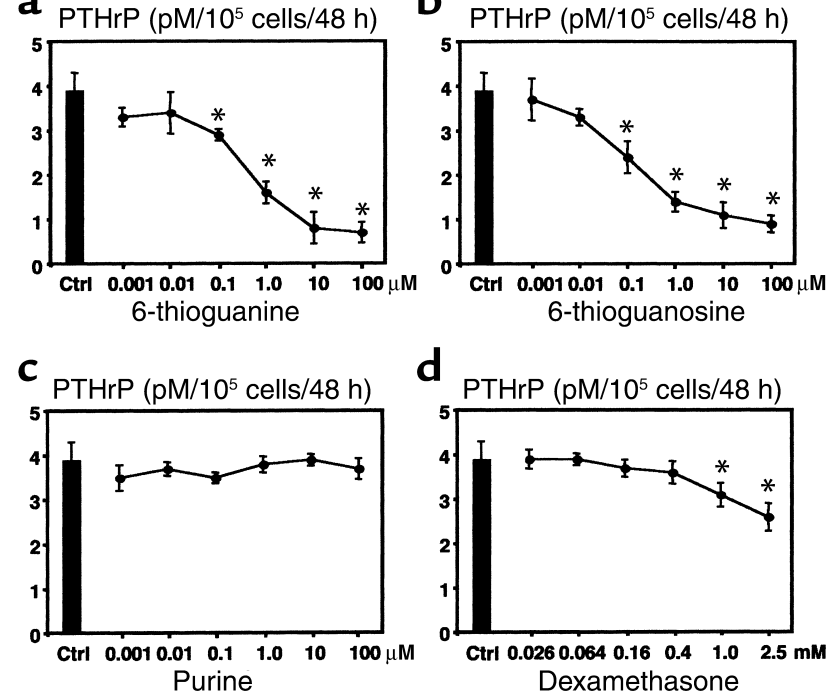

d

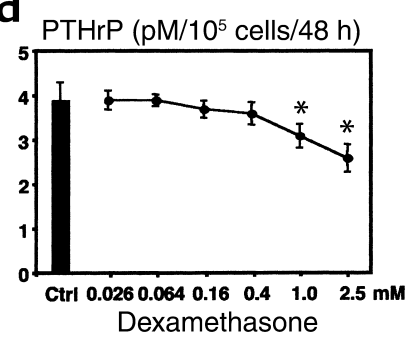

Figure 1

(a) Effects of 6-thioguanine on PTHrP content in the media of cultured MDA-MB-231 cells plated onto 48-well plates and grown to near confluence. Cells were washed and treated with serum-free media containing 6-thioguanine in the indicated concentrations for 48 hours. PTHrP concentrations in conditioned media were corrected for cell number. The detection limit of the assay is $\sim 0.5 \mathrm{pM} / \mathrm{L}$. (b) Effects of 6-thioguanosine on PTHrP content in the media of cultured MDA-MB-231 cells plated onto 48-well plates and treated as described in a. (c) Effects of purine on PTHrP content in the media of cultured MDA-MB-231 cells plated onto 48-well plates and treated as described in $\mathbf{a}$. (d) Effects of dexamethasone on PTHrP content in the media of cultured MDA-MB-231 cells plated onto 48-well plates and treated as described in a. Values in all panels represent means $\pm \operatorname{SEM}\left(n=3\right.$ per group). Ctrl, control. ${ }^{*} P<0.05$.

Isolation of cellular RNA. In six-well tissue-culture plates (Greiner, Frickenhausen, Germany), $2 \times 10^{5}$ MDA-MB231 cells were cultured in DMEM (Mediatech), 10\% FCS (HyClone Laboratories), 1\% penicillin/streptomycin, and $1 \%$ L-glutamine (Mediatech). Cells were cultured for 24 hours in a $37^{\circ} \mathrm{C}$ atmosphere of $5 \% \mathrm{CO}_{2}$ and $95 \%$ $\mathrm{O}_{2}$. Cells were washed twice in PBS, and the compound was added in DMEM, 2.5\% FCS, $1 \%$ penicillin/streptomycin, and $1 \% \mathrm{~L}$-glutamine. Stock $1 \mathrm{mM}$ solutions of purine, 6-thioguanine, and 6-thioguanosine (SigmaAldrich) were prepared in DMEM, 2.5\% FCS, 10\% DMSO, and $2 \%$ methyl- $\beta$-cyclodextrin (Sigma-Aldrich). Cells were cultured for 24 hours in a $37^{\circ} \mathrm{C}$ atmosphere of $5 \% \mathrm{CO}_{2}$ and $95 \% \mathrm{O}_{2}$. Cells were washed twice in PBS, and RNA was isolated on the basis of the method of Chomczynski and Sacchi (18).

Reverse transcription. Reverse transcription of all samples was performed under the following conditions: $2 \mu \mathrm{g}$ of total RNA, $0.5 \mu \mathrm{g}$ of oligo(dT) ${ }_{12-18}$, and $12 \mu \mathrm{l}$ of sterile, distilled water. Samples were incubated for 10 minutes at $70^{\circ} \mathrm{C}$ and quick-chilled on ice. The denatured RNA was added to $50 \mathrm{mM}$ Tris- $\mathrm{HCl}$ ( $\mathrm{pH} \mathrm{8.3),} 75 \mathrm{mM} \mathrm{KCl}, 3$ $\mathrm{mM} \mathrm{MgCl} 2,10 \mathrm{mM}$ DTT, $0.5 \mathrm{mM}$ deoxynucleotide triphosphates (dNTPs), and 200 U Superscript II RNase $\mathrm{H}^{-}$reverse transcriptase (Gibco BRL; Life Technologies
Inc., Rockville, Maryland, USA) to a final volume of 20 $\mu l$. Mixtures were incubated for 50 minutes at $42^{\circ} \mathrm{C}$ and inactivated by heating at $70^{\circ} \mathrm{C}$ for 15 minutes.

Competitive PCR. To correct for any variation in RNA content and cDNA synthesis, all samples were equalized on the basis of their $\beta 2$-microglobulin content. Procedures have been described elsewhere in detail (19-21). Briefly, human-specific primer sets were used to identify steady-state mRNA concentrations for the housekeeping gene $\beta 2$-microglobulin and PTHrP. Ten nanograms of sample cDNA were coamplified in a Perkin Elmer DNA Thermal Cycler 480 (Norwalk, Connecticut, USA) with human-specific $\beta 2$-microglobulin over 32 cycles in the presence of five fourfold serial dilutions of the internal standard PQA1, generously provided by G. van der Pluijm (Leiden University Medical Center, Leiden, the Netherlands).

Competitive PCR was performed under the following conditions: $50 \mu \mathrm{l}$ of reaction volume containing 20 $\mathrm{mM}$ Tris- $\mathrm{HCl}$ ( $\mathrm{pH}$ 8.4), $50 \mathrm{mM} \mathrm{KCl,} 2 \mathrm{mM} \mathrm{MgCl}, 0.2$ mM dNTPs, 1 U Taq DNA polymerase (Gibco BRL; Life Technologies Inc.), $0.25 \mu \mathrm{M}$ sense and antisense primers, 10 ng of cDNA, and PQA1 internal standard to be coamplified. Cycle conditions were as follows: initial denaturing at $94^{\circ} \mathrm{C}$ for 30 seconds and 32 cycles at $94^{\circ} \mathrm{C}$ for 30 seconds, $56^{\circ} \mathrm{C}$ for 30 seconds, and $72^{\circ} \mathrm{C}$ for 60 seconds, followed by 1 cycle at $72^{\circ} \mathrm{C}$ for $2 \mathrm{~min}$ utes. Electrophoresis of $10 \mu \mathrm{l}$ of aliquots of all samples were run on $1.25 \%$ agarose gels (Gibco BRL; Life Technologies Inc.) containing $0.5 \mu \mathrm{g}$ of ethidium bromide per milliliter. Gel images were captured using the EDAS Image Capture System (Kodak DC120 camera, Kodak Digital Science 1D 3.0.2 software; Eastman Kodak Co.) and analyzed with the Quantity One 4.2.2 software package (Bio-Rad Laboratories). The internal standard PQA1 amplicon for $\beta 2$-microglobulin had a size of $370 \mathrm{bp}$, and the sample amplicon size for $\beta 2$-microglobulin was $268 \mathrm{bp}$.

Steady-state PTHrP $m R N A$ expression. After normalization of samples to $\beta 2$-microglobulin, steady-state mRNA concentrations were determined for PTHrP. Procedures have been described elsewhere in detail (21). Briefly, semiquantitative PCR was performed under the following conditions: $50 \mu \mathrm{l}$ reaction volume containing $20 \mathrm{mM}$ Tris- $\mathrm{HCl}$ ( $\mathrm{pH} 8.4$ ), $50 \mathrm{mM} \mathrm{KCl,} 2$ $\mathrm{mM} \mathrm{MgCl} 2,0.2 \mathrm{mM}$ dNTPs, 1 U Taq DNA polymerase (Gibco BRL; Life Technologies Inc.), $0.25 \mu \mathrm{M}$ sense and antisense PTHrP primers, and sample cDNA normalized to $\beta 2$-microglobulin. Cycle conditions were as follows: initial denaturing at $94^{\circ} \mathrm{C}$ for 30 seconds and 32 cycles at $94^{\circ} \mathrm{C}$ for 30 seconds, $56^{\circ} \mathrm{C}$ for 30 seconds, $72^{\circ} \mathrm{C}$ for 60 seconds, followed by 1 cycle at $72^{\circ} \mathrm{C}$ for 2 minutes. Electrophoresis of $10 \mu \mathrm{l}$ of aliquots of all samples were run on $1.25 \%$ agarose gels (Gibco BRL; Life Technologies Inc.) containing $0.5 \mu \mathrm{g}$ of ethidium bromide per milliliter. Gel images were captured with the EDAS Image Capture System (Kodak DC120 camera, Kodak Digital Science 1D 3.0.2 software; Eastman Kodak Co.) and analyzed with the Quantity One 4.2.2 


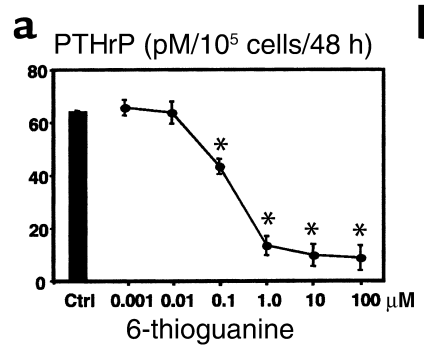

b PTHrP (pM/105 cells/48 h)

\section{C}
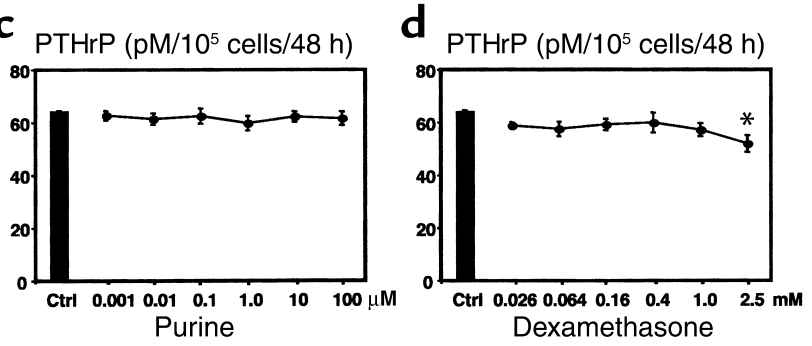

Figure 2

(a) Effects of 6-thioguanine on PTHrP content in the media of cultured RWGT2 cells plated onto 48-well plates and grown to near confluence. Cells were washed and treated with serum-free media containing 6-thioguanine in the indicated concentrations for 48 hours. PTHrP concentrations in conditioned media were corrected for cell number. The detection limit of the assay is $\sim 0.5 \mathrm{pM} / \mathrm{L}$. (b) Effects of 6-thioguanosine on PTHrP content in the media of cultured RWGT2 cells plated onto 48-well plates and treated as described in a. (c) Effects of purine on PTHrP content in the media of cultured RWGT2 cells plated onto 48-well plates and treated as described in a. (d) Effects of dexamethasone on PTHrP content in the media of cultured RWGT2 cells plated onto 48-well plates and treated as described in $\mathbf{a}$. Values in all panels represent means \pm SEM ( $n=3$ per group). Ctrl, control. ${ }^{*} P<0.05$.

software package (Bio-Rad Laboratories). The sample amplicon size for PTHrP was $423 \mathrm{bp}$.

Cytokine assay. Immunoreactive IL-6, IL-11, or VEGF concentrations were measured in the conditioned media of compound-treated MDA-MB-231, RWGT2, MCF-7, and ZR-75 cell lines with the use of quantitative sandwich enzyme immunoassay kits (R\&D Systems, Minneapolis, Minnesota, USA). This assay utilizes a monoclonal antibody specific for IL-6, IL-11, or VEGF precoated onto a microplate. Samples were prepared as follows: cell lines were plated in six-well plates at a density of $2.5 \times 10^{5}$ cells/well, incubated for 24 hours at $37^{\circ} \mathrm{C}$, and washed twice in PBS. Cells were incubated for 24 hours with the compound, and conditioned medium was removed and stored at $-70^{\circ} \mathrm{C}$ until analysis.

Statistical analysis. All results are expressed as means \pm SEM. Data were analyzed by the paired two sample for means $t$ test. The log-rank test (Wilcoxon survival) was used to analyze survival data. A $P$ value less than 0.05 was considered significant.

\section{Results}

Identification of compounds that inbibit PTHrP production. In a search for compounds that regulate PTHrP production by cancer cells, we examined a number of anticancer agents that have previously been reported to have beneficial effects in patients with advanced disease. Among these compounds were the nucleotide analogs 6-thioguanine and 6-thioguanosine, which effectively reduced $\mathrm{PTHrP}$ production in both MDA-MB-231 cells (Figure 1, a and b) and RWGT 2 cells (Figure 2 , a and b) at 1,10 , and $100 \mu \mathrm{M}$. These compounds did not affect cell proliferation as determined by ${ }^{3} \mathrm{H}$-thymidine uptake (data not shown). Purine, an analog of 6-thioguanine and 6-thioguanosine, did not reduce $\mathrm{PTHrP}$ production in MDA-MB-231 cells (Figure 1c) or RWGT2 cells (Figure 2c) at concentrations from 0.001 to $100 \mu \mathrm{M}$. Dexamethasone has been reported to significantly reduce PTHrP production in MDA-MB-231 cells (22), but the inhibitory effects exerted by the nucleotide analogs were significantly more striking at concentrations 2500 -fold lower than those required for glucocorticoid-dependent effects (compare Figure 1b with Figure 2b and Figure 1d with Figure 2d).

Effects of 6-thioguanine and 6-thioguanosine on PTHrP promoter activity and steady-state PTHrP mRNA concentrations in MDA-MB- 231 cells. To test the effects of these guanosine analogs on PTHrP promoter activity, we used MDA-MB-231 cells stably transfected with the firefly luciferase gene operatively linked to the $1.1 \mathrm{~kb}$ fragment of the 5 '-flanking region of the PTHrP gene. After 24 hours of treatment with 6-thioguanine (1 and $10 \mu \mathrm{M})$ and 6-thioguanosine (1 and $10 \mu \mathrm{M}$ ), there was an approximately $70 \%$ decrease
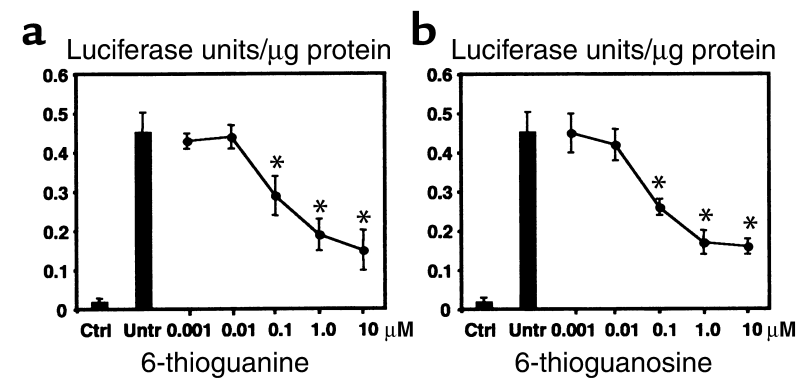

c

Luciferase units/ $\mu \mathrm{g}$ protein
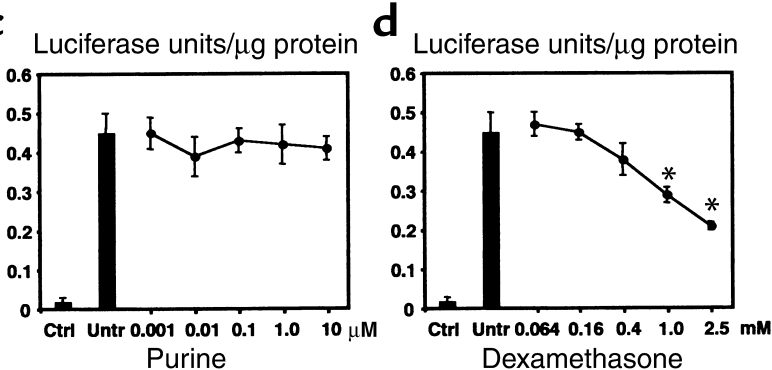

Figure 3

(a) Effect of 6-thioguanine on the $1.1 \mathrm{~kb} 5^{\prime}$-flanking region of the PTHrP gene. (b) Effect of 6-thioguanosine on the $1.1 \mathrm{~kb} 5^{\prime}$-flanking region of the PTHrP gene. (c) Effect of purine on the $1.1 \mathrm{~kb}$ 5'-flanking region of the PTHrP gene. (d) Effect of dexamethasone on the $1.1 \mathrm{~kb} 5^{\prime}$-flanking region of the PTHrP gene. Values in all panels represent means \pm SEM ( $n=3$ per group). Ctrl, control; Untr, MDA-MB-231 cells stably transfected with the $1.1 \mathrm{~kb}$ 5 '-flanking region/luciferase reporter gene. ${ }^{*} P<0.05$. 


\section{Table 1}

Comparison of the inhibitory effects of 6-thioguanine and 6-thioguanosine on various promoter-luciferase constructs in various host-cell lines

\begin{tabular}{lccc} 
Cell line & Promoter construct & \multicolumn{2}{c}{ \% inhibition } \\
& & $\begin{array}{c}\text { 6-Thioguanine } \\
(1 \mu \mathrm{M})\end{array}$ & 6-Thioguanosine \\
& & $69 \pm 2.4^{\mathrm{A}}$ & $64 \pm 3.1^{\mathrm{A}}$ \\
MDA-MB-231 & PTHrP-luciferase & $3 \pm 0.3$ & $4 \pm 0.1$ \\
MG63 & CRE/SRE-luciferase & $9 \pm 0.6$ & $7 \pm 0.5$ \\
MDA-MB-231 & CMV-luciferase & $4 \pm 0.2$ & $5 \pm 0.1$ \\
2T3 & BMP2-luciferase & $3 \pm 0.4$ & $3 \pm 0.4$ \\
2T3 & BMP4-luciferase & $1 \pm 0.01$ & $1 \pm 0.04$ \\
MG63 & IL6-luciferase &
\end{tabular}

Cell-culture conditions are described in the Methods. ${ }^{A} P<0.05$.

in firefly luciferase activity (Figure 3 , a and b). Purine, an analog of 6-thioguanine and 6-thioguanosine (Figure 3c), had no effect.

To confirm the specificity of the effects, we tested 9,600 randomly defined chemical compounds from a diverse commercial library (MicroSource). Only 6-thioguanine and one other compound were found to specifically inhibit the PTHrP promoter activity in the absence of cell toxicity. We tested 6-thioguanine and a series of other antimetabolite compounds on other promoters unrelated to $\mathrm{PTHrP}$, which were operatively linked to firefly luciferase. These promoters included CRE/SRE in MG63 cells, the CMV promoter in MDA-MB-231 cells, the BMP-2 promoter in 2T3 cells, the BMP-4 promoter in $2 \mathrm{~T} 3$ cells, and the IL-6 promoter in MG63 cells. Only 6-thioguanine and the closely related compound 6-thioguanosine specifically inhibited the PTHrP promoter construct without affecting the aforementioned promoter activities (Table 1).

To determine the effects of 6-thioguanine and 6-thioguanosine on steady-state PTHrP mRNA concentrations, MDA-MB-231 cells were treated for 24 hours with $0.1,1,10$, or $100 \mu \mathrm{M} 6$-thioguanine or 6-thioguanosine followed by extraction of RNA. After $\beta 2$-microglobulin normalization, steady-state mRNA concentrations of PTHrP (after treatment with $0.1,1,10$, or $100 \mu \mathrm{M}$ purine, 6-thioguanine, or 6-thioguanosine) were quantified (Figure 4b). Purine did not affect steady-state mRNA concentrations of PTHrP, whereas 100, 10, and $1 \mu \mathrm{M}$ 6-thioguanine and 6-thioguanosine reduced steady-state mRNA concentrations of PTHrP by as much as $50 \%$.

Effects of 6-thioguanine and 6-thioguanosine on IL-1, IL-6, IL-11, and VEGF production in various cell lines. To confirm the specificity of these compounds on PTHrP production, two additional human breast-cancer cell lines, MCF-7 and ZR-75, and four other cytokines were examined, including IL-1, IL-6, IL-11, and VEGF. We compared the effects of the compounds on the presence of cytokines in the conditioned media of cells cultured for 48 hours. The cytokines were measured by
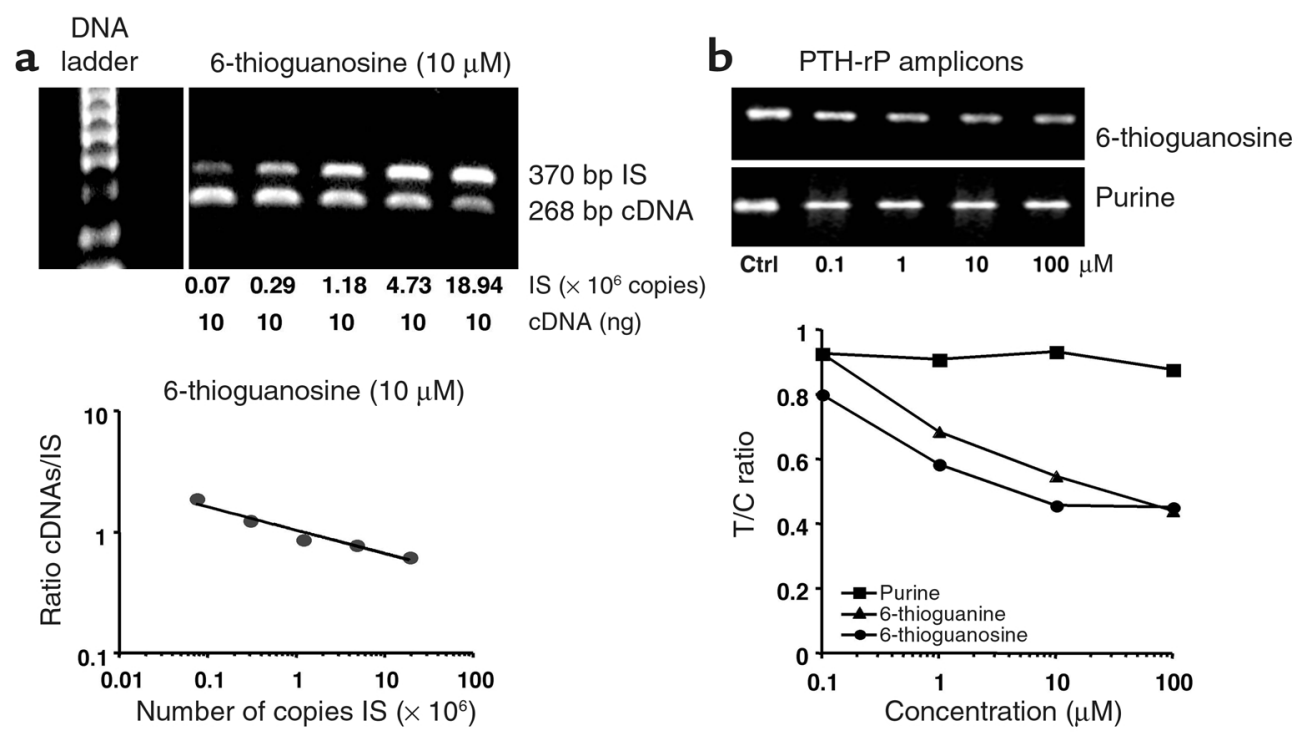

Figure 4

(a) Competitive PCR analysis of $\beta 2$-microglobulin mRNA levels in MDA-MB-231 cells treated with 6-thioguanosine. Ten nanograms of cDNA from MDA-MB-231 cells treated with $10 \mu \mathrm{M}$ 6-thioguanosine were amplified with five fourfold serial dilutions of pQA1 internal standard (IS). The cDNA was amplified under the following PCR conditions: 32 cycles, annealing temperature of $56^{\circ} \mathrm{C}$, and $2 \mathrm{mM} \mathrm{MgCl} 2 .(\mathbf{b}) \mathrm{Effect}$ of purine, 6-thioguanine, and 6-thioguanosine on steady-state mRNA levels of PTHrP in MDA-MB-231 cells. After normalization of cDNA to $\beta 2$-microglobulin from MDA-MB-231 cells treated with $0.1,1,10$, or $100 \mu \mathrm{M}$ purine, 6-thioguanine, or 6-thioguanosine, samples were amplified under the following semiquantitative PCR conditions: 32 cycles, annealing temperature of $56^{\circ} \mathrm{C}$, and $2 \mathrm{mM} \mathrm{MgCl}$. $\mathrm{Human}_{\mathrm{spe}}$ cific sense and antisense primers to PTHrP were used. The figure represents the detection and quantitation of steady-state mRNA levels of PTHrP when treated with $100,10,1$, and $0.1 \mu \mathrm{M}$ purine, 6-thioguanine, or 6-thioguanosine, expressed as treated-to-control (T/C) ratios. Purine did not affect steady-state mRNA levels of PTHrP, whereas 100, 10, and $1 \mu \mathrm{M} 6$-thioguanine and 6-thioguanosine reduced steadystate mRNA levels of PTHrP by as much as $50 \%$. 
Table 2

Comparison of the effects of dexamethasone, 6-thioguanine, and 6-thioguanosine on IL-6 production ( $\mathrm{pg} / \mathrm{ml}$ ) by MDA-MB-231, RWGT2, MCF-7, and ZR-75 cell lines

\begin{tabular}{lcccc} 
Cell line & \multicolumn{4}{c}{ Treatment } \\
& Control & $\begin{array}{c}\text { Dexamethasone } \\
(1.0 \mathrm{mM})\end{array}$ & $\begin{array}{c}\text { 6-Thioguanine } \\
(10 \mu \mathrm{M})\end{array}$ & 6-Thioguanosine \\
& & $(10 \mu \mathrm{M})$ \\
MDA-MB-231 & $360.4 \pm 6.9$ & $18.9 \pm 0.6^{\mathrm{A}}$ & $430.4 \pm 21$ & $395.8 \pm 38$ \\
RWGT2 & $116.9 \pm 1.7$ & $120.9 \pm 9.3$ & $104.5 \pm 30.8$ & $95.8 \pm 5.8$ \\
MCF-7 & $3.3 \pm 0.2$ & $1.7 \pm 0.5^{\mathrm{A}}$ & $1.5 \pm 0.7^{\mathrm{A}}$ & $3.5 \pm 0.9$ \\
ZR-75 & $\mathrm{ND}$ & $\mathrm{ND}$ & $\mathrm{ND}$ & $\mathrm{ND}$ \\
\hline
\end{tabular}

Values represent means $\pm \operatorname{SEM}\left(n=3\right.$ per group). ND, not detected. ${ }^{A} P<0.05$.

ELISA (Tables 2-4). IL-1 could not be detected with or without compounds. IL- 6 was present in the conditioned media $(360.4 \pm 6.9 \mathrm{ng} / \mathrm{ml})$ but was unaffected by either compound in concentrations of $10,1,0.1$, and $0.01 \mu \mathrm{M}$ (means + SEM, $n=3$ ). Similarly, IL-11 was present $(239.9 \pm 3.1 \mathrm{ng} / \mathrm{ml})$ but was unaffected by either compound in the same concentration ranges. VEGF was present in concentrations of $1258.2 \pm 33.8$ $\mathrm{ng} / \mathrm{ml}$ but was also unaffected by addition to cells of any of the concentrations of either compound.

Effects of 6-thioguanine and 6-thioguanosine on breast-cancer metastases to bone. To determine the effects of 6-thioguanine and 6-thioguanosine on the capacity of human breast-cancer cells to cause osteolytic bone lesions, 6-thioguanine and 6-thioguanosine were studied in female nude athymic mice injected with MDA-MB-231 cells. Representative radiographs were taken during the course of the experiments to quantify the progression of metastasis. In untreated mice, the tumor lesion area was $3.97 \pm 1.48 \mathrm{~mm}^{2}$, as compared with $0.74 \pm 0.14 \mathrm{~mm}^{2}$ in mice treated daily with 6 -thioguanine $(1.0 \mathrm{mg} / \mathrm{kg} /$ day, $P<0.05)$ (Figure $5 \mathrm{a})$. Radiographs taken 28 days after tumor inoculation (Figure $5 \mathrm{~b}$ ) show that the untreated group had an osteolytic-lesion area of $9.63 \pm 0.88 \mathrm{~mm}^{2}$. Daily treatment with 6 -thioguanosine $(0.1 \mathrm{mg} / \mathrm{kg} /$ day $)$ reduced the osteolytic-lesion area to $2.36 \pm 1.53 \mathrm{~mm}^{2}(P<0.05)$ (Figure 6a). Radiographs taken 28 days after tumor inoculation (Figure 6b) illustrate the similar efficacy of 6-thioguanosine in decreasing the area of osteolytic bone lesions. Mice treated with 6-thioguanine $(0.5$ $\mathrm{mg} / \mathrm{kg} /$ day $)$ or 6 -thioguanosine $(0.5 \mathrm{mg} / \mathrm{kg} /$ day $)$ beginning on day 15 , after bone lesions had formed, had a significant reduction in osteolytic-lesion area from $7.05 \pm 0.81 \mathrm{~mm}^{2}$ in the untreated group to $3.16 \pm 0.54 \mathrm{~mm}^{2}$ in the group treated with 6-thioguanine $(P<0.05)$ and $3.39 \pm 084 \mathrm{~mm}^{2}$ in the group treated with 6-thioguanosine $(P<0.05)$ (Figure 7).

Because radiographic methods assess only bone destruction and do not directly measure tumor area in bone, histomorphometric analysis of hindlimb bones was performed. The untreatedtumor group had an osteoclast number

\section{Table 3}

Cell line per millimeter of tumor-bone interface of $15.62 \pm 0.93$. In mice treated with 6 -thioguanine $(1.0 \mathrm{mg} / \mathrm{kg} /$ day $)$, the osteoclast number per millimeter of tumor-bone interface was $2.81 \pm 1.74$; for 6 -thioguanosine treatment $(1.0 \mathrm{mg} / \mathrm{kg} /$ day $)$, the osteoclast number per millimeter of tumorbone interface was $4.07 \pm 2.53$. Both 6-thioguanine and 6-thioguanosine significantly reduced the osteoclast number per millimeter of tumor-bone interface, as compared with the effects in mice that were not treated $(P<0.05)$ (Figure 8 ).

In two separate experiments, the survival of mice treated with 6-thioguanine and 6-thioguanosine was examined. In the first experiment (Figure 9a), all mice in the untreated-tumor group had died by day 35 , whereas $80 \%$ of the mice treated from day 1 with 6-thioguanine or 6-thioguanosine $(1.0 \mathrm{mg} / \mathrm{kg} / \mathrm{day})$ were still alive $(P<0.05)$. In the second experiment (Figure $9 b)$, all mice in the untreated tumor group had died by day 32 , whereas $80 \%$ of the mice treated from day 15 with 6-thioguanine or 6-thioguanosine $(1.0 \mathrm{mg} / \mathrm{kg} / \mathrm{day})$ were still alive $(P<0.05)$.

Specificity of effects of 6-thioguanine and 6-thioguanosine on $P T H r P$ promoter activity in vivo. The data in Figures 1 and 2 indicate that 6-thioguanine and 6-thioguanosine inhibit PTHrP expression in vitro. To confirm that the target of these compounds in vivo is the PTHrP promoter, we examined the effects of 6-thioguanine and 6-thioguanosine on human breast-cancer cells transfected with PTHrP driven by a strong nonspecific general promoter. MDA-MB-231 cells stably transfected with the cDNA for human preproPTHrP driven by a CMV promoter were inoculated into the left cardiac ventricle of female nude athymic mice, and the capacity of the inoculum to cause osteolytic bone lesions was assessed. This tumor-cell line expresses $100 \mathrm{pM} \mathrm{PTHrP} / 24$ hours, as compared with the wild-type MDA-MB-231 cell line, which expresses $8.4 \mathrm{pM} \mathrm{PTHrP} / 24$ hours. Representative radiographs were taken during the course of the experiments to quantify the progression of metastasis.

Mice injected with the MDA-MB-231 cells overexpressing PTHrP were treated with either 6-thioguanine or 6-thioguanosine. On day 21 , the untreated-tumor group had an osteolytic-lesion area of $4.7 \pm 2.3 \mathrm{~mm}^{2}$, as

Comparison of the effects of dexamethasone, 6-thioguanine, and 6-thioguanosine on IL-11 production ( $\mathrm{pg} / \mathrm{ml}$ ) by MDA-MB-231, RWGT2, MCF-7, and ZR-75 cell lines

Treatment

$\begin{array}{lcccc} & \text { Control } & \begin{array}{c}\text { Dexamethasone } \\ (1.0 \mathrm{mM})\end{array} & \begin{array}{c}\text { 6-Thioguanine } \\ (10 \mu \mathrm{M})\end{array} & \begin{array}{c}\text { 6-Thioguanosine } \\ (10 \mu \mathrm{M})\end{array} \\ \text { MDA-MB-231 } & 239.9 \pm 3.1 & 100.9 \pm 2.5^{\mathrm{A}} & 192.6 \pm 21 & 206.8 \pm 8.6 \\ \text { RWGT2 } & \mathrm{ND} & \mathrm{ND} & \mathrm{ND} & \mathrm{ND} \\ \text { MCF-7 } & \mathrm{ND} & \mathrm{ND} & \mathrm{ND} & \mathrm{ND} \\ \text { ZR-75 } & \mathrm{ND} & \mathrm{ND} & \mathrm{ND} & \mathrm{ND}\end{array}$

Values represent means $\pm \operatorname{SEM}\left(n=3\right.$ per group). ND, not detected. ${ }^{A} P<0.05$. 
Table 4

Comparison of the effects of dexamethasone, 6-thioguanine, and 6-thioguanosine on VEGF production (pg/ml) by MDA-MB-231, RWGT2, MCF-7, and ZR-75 cell lines.

Cell line

$\begin{array}{lc} & \text { Control } \\ & \\ \text { MDA-MB-231 } & 1258.2 \pm 33.8 \\ \text { RWGT2 } & 1232.5 \pm 13.7 \\ \text { MCF-7 } & 167.1 \pm 3.4 \\ \text { ZR-75 } & 99.0 \pm 1.5\end{array}$

Treatment

$\begin{array}{cc}\begin{array}{cc}\text { Dexamethasone } \\ (1.0 \mathrm{mM})\end{array} & \begin{array}{c}\text { 6-Thioguanine } \\ (10 \mu \mathrm{M})\end{array} \\ 1068.2 \pm 14.5 & 1041.9 \pm 56.8 \\ 1328.9 \pm 46.8 & 1300.9 \pm 30.7 \\ 180.1 \pm 2.0 & 56.5 \pm 7.2^{\mathrm{A}} \\ 99.8 \pm 2.3 & 97.0 \pm 1.1\end{array}$

Values represent means $\pm \operatorname{SEM}\left(n=3\right.$ per group). ${ }^{A} P<0.05$

compared with an osteolytic lesion area of $3.9 \pm 0.7 \mathrm{~mm}^{2}$ for mice treated with 6 -thioguanine $(1.0 \mathrm{mg} / \mathrm{kg} /$ day $)$ (Table 5). On day 21, the untreated-tumor group had an osteolytic-lesion area of $7.2 \pm 1.0 \mathrm{~mm}^{2}$, as compared with an osteolytic lesion area of $8.5 \pm 1.9 \mathrm{~mm}^{2}$ in mice treated with 6-thioguanosine $(1.0 \mathrm{mg} / \mathrm{kg} /$ day $)$ (Table 5). Thus, unlike their effects on osteolytic lesions caused by wild-type MDA-MB-231 cells, the purine analogs did not reduce the area of osteolytic lesions caused by tumor cells overexpressing PTHrP by the CMV promoter. These findings are consistent with the premise that 6-thioguanine and 6-thioguanosine exert their inhibitory effects by selectively affecting PTHrP expression driven by the endogenous promoter.

Effects of 6-thioguanine and 6-thioguanosine on tumor growth and tumor burden. To determine the effects of 6-thioguanine and 6-thioguanosine on tumor growth and tumor burden, athymic nude mice bearing MDAMB-231 cells were studied. Tumor growth was analyzed after intramuscular injection of $10^{7} \mathrm{MDA}-\mathrm{MB}-231$ cells. Treatment with 6-thioguanine or 6-thioguanosine began the following day and continued for 21 days, after which the mice were sacrificed and tumors were excised, measured, and weighed. Neither 6-thioguanine nor 6thioguanosine, administered subcutaneously at concentrations that are effective in inhibiting breast cancer metastasis to bone $(1.0 \mathrm{mg} / \mathrm{kg}$ body weight/day), had an effect on the weight of tumors growing at the site of implantation (Figure 10a).

Tumor burden in bone was analyzed after intracardiac injection of $10^{5} \mathrm{MDA}-231 \mathrm{~F} 9 \mathrm{AD} / \mathrm{Luc}$ cells (MDAMD-231 cells stably transfected with the firefly luciferase reporter gene) into female athymic nude mice, with 6-thioguanine or 6-thioguanosine treatment beginning the following day. On day 28 , at sacrifice, bone marrow was flushed from the femurs and tibias of the mice and analyzed for luciferase activity. The 6-thioguanine administered subcutaneously at 1.0 $\mathrm{mg} / \mathrm{kg} /$ day significantly reduced tumor burden in bone marrow from $2.34 \pm 0.31$ luciferase $\mathrm{U} / \mathrm{mg}$ protein in the untreated group to $0.52 \pm 0.12$ luciferase $\mathrm{U} / \mathrm{mg}$ protein in the treated group. The 6-thioguanosine reduced tumor burden in bone marrow to $0.71 \pm 0.84$ luciferase $\mathrm{U} / \mathrm{mg}$ protein as measured by luciferase activity in the metastatic tumor cells $(P<0.05)$ (Figure 10b).
6-Thioguanosine $(10 \mu \mathrm{M})$

$1203.5 \pm 47.7$

$1367.7 \pm 59.4$

$134.6 \pm 8.0^{\mathrm{A}}$

$89.2 \pm 9.7$
Effects of 6-thioguanine and 6-thioguanosine on hypercalcemia. To determine the effects of 6-thioguanine and 6-thioguanosine on HHM caused by a human tumor, the compounds were administered to male athymic nude mice previously injected with RWGT2 cells, which express massive amounts of PTHrP leading to increased systemic concentrations. The effects of the compounds were assessed on wholeblood ionized-calcium and serum PTHrP concentrations. The compounds were administered daily for 10 days (10 $\mathrm{mg} / \mathrm{kg} /$ day subcutaneously) after injection of the RWGT2 cells in two schedules, the first at the time of inoculation of the tumor cells and the second after hypercalcemia became evident by measurement of whole-blood ionized-calcium concentrations.

In the first set of experiments, 6-thioguanine or 6thioguanosine was administered daily $(10 \mathrm{mg} / \mathrm{kg} /$ day subcutaneously) from the time of injection of RWGT2
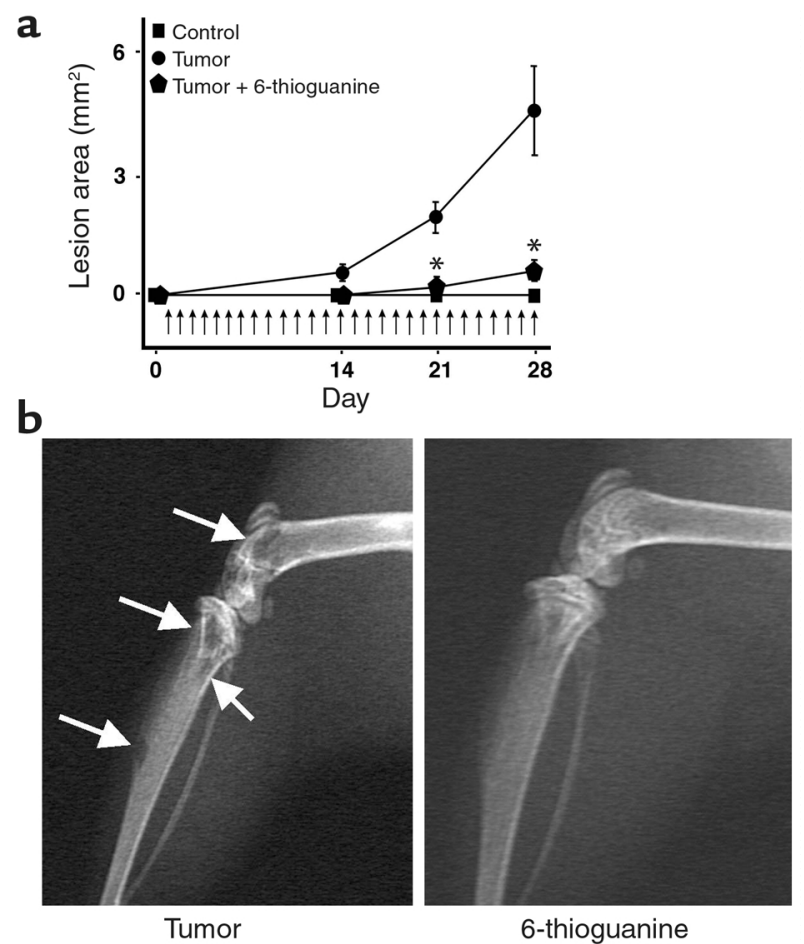

Figure 5

(a) Effect of 6-thioguanine on the area of osteolytic lesions. Osteolytic-lesion area was assessed by Faxitron (model 43855A, Faxitron X-ray Corp.) and computerized image analysis of hindlimb radiographs. MDA-MB-231 tumor cells were inoculated on day 0 . Treatment with 6-thioguanine $(1.0 \mathrm{mg} / \mathrm{kg} /$ day subcutaneously) was begun on the following day. Vertical arrows indicate the days of treatment. Values represent means $\pm \operatorname{SEM}\left(n=5\right.$ per group). ${ }^{*} P<0.05$. (b) Representative radiographs of hindlimbs from mice bearing MDA-MB-231 tumors 28 days after tumor inoculation with and without treatment with 6-thioguanine (Figure 6a). Arrows indicate osteolytic lesions. 
a

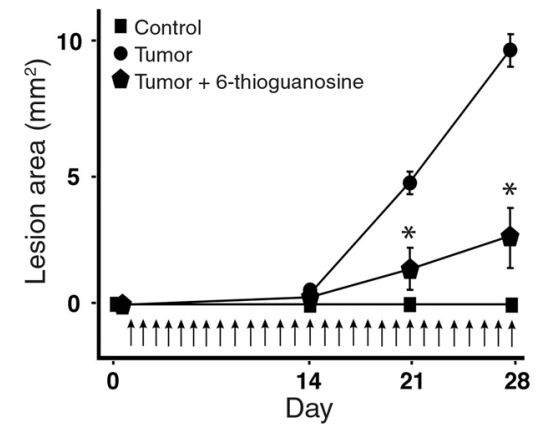

b

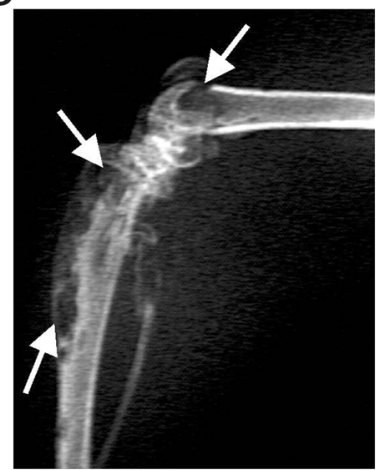

Tumor

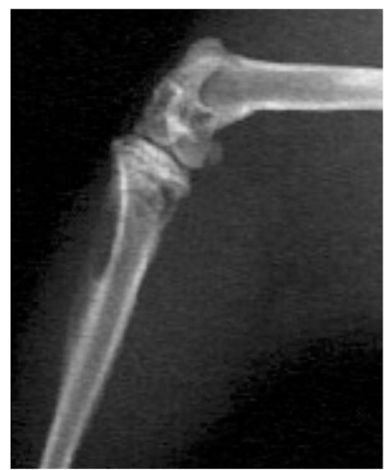

6-thioguanosine

Figure 6

(a) Effect of 6-thioguanosine on the area of osteolytic lesions in mice bearing MDA-MB-231 cells after intracardiac injection. Osteolyticlesion area was assessed by Faxitron (model 43855A, Faxitron X-ray Corp.) and computerized image analysis of hindlimb radiographs. MDA-MB-231 tumor cells were inoculated on day 0 . Treatment with 6-thioguanosine $(0.1 \mathrm{mg} / \mathrm{kg} /$ day subcutaneously) was begun on the following day. Vertical arrows indicate the days of treatment. Values represent means $\pm \operatorname{SEM}\left(n=5\right.$ per group). ${ }^{*} P<0.05$. (b) Representative radiographs of hindlimbs from mice bearing MDA-MB-231 tumors 28 days after tumor inoculation with and without treatment with 6-thioguanosine (Figure 7a). Arrows indicate osteolytic lesions.

cells until the tenth day. Figure 11a shows that 6-thioguanine significantly decreased the mean wholeblood ionized-calcium concentration and also reduced the mean serum PTHrP concentration (Figure 11b); 6-thioguanosine had similar inhibitory effects on whole-blood ionized-calcium (Figure 11c) and serum PTHrP concentrations (Figure 11d).

The effectiveness of 6-thioguanine and 6-thioguanosine in preventing further elevation of whole-blood ionized-calcium and serum PTHrP concentrations after hypercalcemia was present was also examined. In those experiments, 6-thioguanine or 6-thioguanosine was administered daily $(10 \mathrm{mg} / \mathrm{kg} /$ day subcutaneously) beginning 11 days after RWGT2 injection. Again, 6-thioguanine (Figure 12, a and b) and 6-thioguanosine (Figure 12, $\mathrm{c}$ and d) significantly reduced whole-blood ionized-calcium and serum PTHrP concentrations.

\section{Discussion}

We have identified guanosine nucleotide analogs as having the capacity to specifically decrease production of PTHrP by human cancer cells associated with localized

osteolysis and HHM. We have found that in preclinical animal models of these two distinct syndromes associated with excess PTHrP production, there is reduction in localized osteolysis and hypercalcemia, respectively.

Clinical and experimental evidence indicates that tumor-produced PTHrP is a major possible candidate for the osteoclastic bone resorption present at sites of breast cancer metastatic to bone (23-25). Multiple studies have shown the importance of PTHrP production by breast-cancer cells that have metastasized to bone. PTHrP was detected by immunohistochemistry (23) and in situ hybridization (24) in $92 \%$ of breast-cancer metastases in bone, as compared with only $17 \%$ of similar metastases to nonbone sites. This observation prompted speculation that production of PTHrP as a bone-resorbing agent may contribute to the tendency for breast cancers to cause osteolytic metastases. Positive immunohistochemical staining for $\mathrm{PTHrP}$ was found in $56 \%$ of 155 primary breast tumors from normocalcemic women, and PTHrP expression was positively correlated with the development of bone metastases and hypercalcemic episodes (26). PTHrP expression was detected by RT-PCR in 37 of 38 primary breast cancers, and subsequent development of bone metastases was associated with a higher expression of PTHrP (25). In another study, PTHrP was detected by immunohistochemistry in $83 \%$ of patients who developed bone metastases, as compared with $38 \%$ in those who developed lung metastases without recurrence (27).

Osteolytic bone lesions are most frequent in patients with carcinoma of the breast, carcinoma of the lung, and myeloma, the same cancers that are associated with hypercalcemia. Until recently, therapy for bone metastatic lesions was directed solely at the tumor cells. This treatment usually involved chemotherapy or hormonal therapy, local field irradiation, radionuclide therapy, or surgery (28-30). The advent of bisphos-

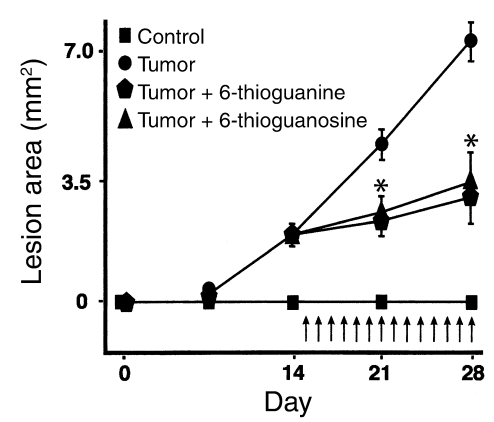

\section{Figure 7}

Effect of 6-thioguanine and 6-thioguanosine on the area of osteolytic lesions. Osteolytic-lesion area was assessed by Faxitron (model 43855A, Faxitron X-ray Corp.) and computerized image analysis of hindlimb radiographs. MDA-MB-231 tumor cells were inoculated on day 0 . Treatment with 6 -thioguanine or 6-thioguanosine $(0.5$ $\mathrm{mg} / \mathrm{kg} /$ day subcutaneously) was begun on day 15 . Vertical arrows indicate the days of treatment. Values represent means \pm SEM ( $n=5$ per group). ${ }^{*} P<0.05$. 


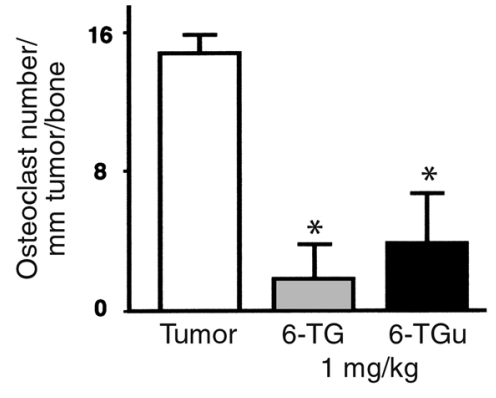

\section{Figure 8}

Effect of 6-thioguanine and 6-thioguanosine on osteoclast number per millimeter of tumor per bone. Data represent histomorphometric analysis of hindlimbs from mice with osteolytic lesions. MDAMB-231 tumor cells were inoculated on day 0 . Treatment with either 6-thioguanine or 6-thioguanosine ( $1.0 \mathrm{mg} / \mathrm{kg} /$ day subcutaneously) was begun on the following day. Measurements are of the number of osteoclasts per millimeter of tumor adjacent to bone (tumor-bone interface) from the midsections of tibias and femurs of mice. Values represent means $\pm \operatorname{SEM}$ ( $n=5$ per group). 6-TG, 6-thioguanine; 6-TGu, 6-thioguanosine. ${ }^{*} P<0.05$.

phonates over the last decade has changed this perspective somewhat; treatment now includes therapy specifically designed to combat osteoclastic bone resorption. It is apparent from clinical studies that the use of bisphosphonates reduces skeleton-related events in advanced breast cancer $(31,32)$. These data suggest that drugs that inhibit bone resorption may be useful adjuvant therapies in patients with malignant disease, and such drugs may have the unanticipated benefit of limiting the growth of tumor cells in the skeleton. As the osteolysis associated with metastatic bone disease is mediated by osteoclastic bone resorption, and as factors that stimulate osteoclastic bone resorption - such as PTHrP - enhance the destruction of bone by tumors, it is logical to consider therapy with inhibitors of bone resorption to delay this progression.

HHM was the first identified consequence of tumor-produced PTHrP in patients with cancer. In this syndrome, PTHrP produced by cancer cells interacts with PTH receptors in bone and kidney to cause hypercalcemia, osteoclast-mediated bone resorption, and increased nephrogenous excretion of cAMP and phosphate (33). The PTHlike properties of PTHrP, and particularly the increase in osteoclastic bone resorption, are responsible for the hypercalcemia. Approximately $80 \%$ of hypercalcemic patents with solid tumors have detectable or increased plasma PTHrP concentrations (34). Plasma PTHrP concentrations are low or undetectable in normal human subjects (35). Mice bearing RWGT2 cells have HHM, but the circumstances are not the same as in patients with the clinical syndrome. The RWGT2 tumors grow to enormous size after subcutaneous implantation, reaching $25 \%$ of the body weight of tumor-bearing mice in just over 2 weeks, and they produce massive circulating PTHrP concentrations (two to three times the concentrations found in patients with HHM) and severe hypercalcemia. Reductions were seen in both $\mathrm{PTHrP}$ and whole-blood ionized-calcium concentrations when 6-thioguanine was administered to mice after the tumor was established. The decreases were clear but relatively modest, since the tumor was also growing rapidly at the time the compound was administered. Similar decreases are apparent when neutralizing antibodies to PTHrP are used (3). When the compounds are administered from the time of tumor inoculation, there is no increase in PTHrP or whole-blood ionized-calcium concentrations.

Treatment of hypercalcemia due to cancer involves treatment of the underlying tumor. Unfortunately, since this is often not effective or cannot be accomplished with the rapidity needed when the patient is faced with life-threatening hypercalcemia, therapy should also be directed against the mechanisms responsible for the hypercalcemia. In essentially all patients with HHM, there is an increase in osteoclastic bone resorption. Current medical therapy is aimed at inhibiting bone resorption and promoting renal calcium excretion. Our earlier data have shown the efficacy of neutralizing antibodies to PTHrP (3), which provides the rationale for directing therapy at $\mathrm{PTHrP}$ production or its effects. Bisphosphonates have become the most useful antiresorptive agents for the treatment of hypercalcemia. Bisphosphonates vary in potency but are poorly absorbed and are most effective in treating hypercalcemia when given intravenously. There is clear evidence that tumor-produced factors can modulate the end-

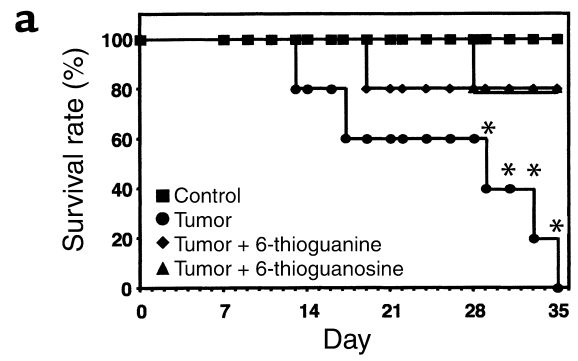

b

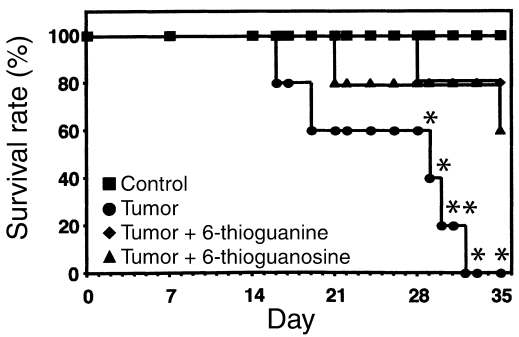

Figure 9

(a) Effect of 6-thioguanine and 6-thioguanosine on survival. MDA-MB231 tumor cells were inoculated on day 0 . Treatment with 6-thioguanine or 6-thioguanosine $(1.0 \mathrm{mg} / \mathrm{kg} /$ day subcutaneously) was begun on the following day. (b) Effect of 6-thioguanine and 6-thioguanosine on survival. MDA-MB-231 tumor cells were inoculated on day 0 . Treatment with 6-thioguanine or 6-thioguanosine $(1.0 \mathrm{mg} / \mathrm{kg} /$ day subcutaneously) was begun on day 15 . For both panels, the log-rank test (Wilcoxon survival) was used to analyze survival data. ${ }^{*} P<0.05$ was considered significant ( $n=5$ per group). 


\section{Table 5}

Comparison of the effect of 6-thioguanine and 6-thioguanosine on area $\left(\mathrm{mm}^{2}\right)$ of osteolytic lesions in mice bearing MDA-MB-231 cells stably transfected with PTHrP driven by the CMV promoter and overexpressing PTHrP, as compared with mice bearing wild-type MDAMB-231 cells

\begin{tabular}{lcc}
\hline & MDA-MB-231 cells & \\
Experiment 1 & Wild type & Stably transfected \\
Control & 0 & 0 \\
Tumor & $6.0 \pm 1.9$ & $4.7 \pm 2.3$ \\
Tumor + 6-thioguanine & $0.4 \pm 0.2^{\mathrm{A}}$ & $3.9 \pm 0.7$ \\
Experiment 2 & & \\
Control & 0 & 0 \\
Tumor & $6.7 \pm 1.2$ & $7.2 \pm 1.0$ \\
Tumor + 6-thioguanosine & $1.6 \pm 0.8^{\mathrm{A}}$ & $8.5 \pm 1.9$
\end{tabular}

Osteolytic lesion area was assessed by Faxitron (model 43855A, Faxitron X-ray Corp.) and computerized image analysis of hindlimbs. MDA-MB-231 tumor cells overexpressing PTHrP or wild-type MDA-MB-231 cells were injected on day 0 . Treatment with 6-thioguanine or 6-thioguanosine (1.0 $\mathrm{mg} / \mathrm{kg} /$ day subcutaneously) was begun on the following day. Values represent means $\pm \operatorname{SEM}\left(n=5\right.$ per group). ${ }^{A} P<0.05$.

organ effects of PTHrP as well as its secretion from tumors. We have shown that when Chinese hamster ovarian $(\mathrm{CHO})$ cells are transfected with PTHrP and inoculated into nude mice, the mice develop hypercalcemia as well as increased osteoclastic bone resorption (36). When CHO cells expressing transfected IL-6 are inoculated into these mice, the hypercalcemia and bone resorption mediated by PTHrP are potentiated by stimulation of the production of early osteoclast precursors (37). Likewise, TGF- $\alpha$ has been shown to enhance the hypercalcemic effects of PTHrP in an animal model of malignancy-associated hypercalcemia (1) and to modulate the effects of PTHrP on bone $(38,39)$. IL-1 $\alpha$ and PTHrP may have synergistic effects in vivo (39), whereas tumor necrosis factor $\alpha$ (TNF- $\alpha$ ) enhanced the hypercalcemic effect of PTHrP by increasing the pool of committed osteoclast progenitors, with a subsequent increase in osteoclastic bone resorption (40).

Other tumor-associated factors appear to be important regulators of PTHrP expression and secretion by tumors. EGF has been shown to stimulate PTHrP expression in a keratinocyte line (41) as well as a mammary epithelial line (42), whereas TGF- $\alpha$ enhanced PTHrP expression in a human squamous-cell carcinoma of the lung (43). IL-6, TNF- $\alpha$, insulin growth factor 1 , and insulin growth factor 2 may increase the production of PTHrP in vitro by a human squamous-cell carcinoma (44). TGF- $\beta$, which is abundant in bone, is released in active form by resorbing bone and is expressed by some breast-cancer cell lines $(45,46)$ and cancer-associated stromal cells (47). It has been shown to enhance secretion of and to stabilize the mRNA for $\mathrm{PTHrP}$ in a renal-cell carcinoma (48) as well as in a squamous-cell carcinoma $(49,50)$. Other data $(51)$ demonstrate that this relationship also exists in a human breast adenocarcinoma-cell line, MDA-MB-231.

The data presented here raise new possibilities for targeted therapy in patients with clinical syndromes of
PTHrP excess, not only for osteolytic lesions caused by metastatic breast cancer but also for PTHrP-mediated hypercalcemia. These results show that 6-thioguanine and 6-thioguanosine mediate their actions by inhibiting PTHrP mRNA and protein expression by cancer cells, and they confirm the central role that PTHrP plays in the pathophysiology of osteolytic metastasis caused by breast cancer as well as in HHM caused by squamous-cell carcinoma.

Guanosine metabolites have been used for many years in the treatment of patients with cancer $(52,53)$. They have been used predominantly in the treatment of childhood leukemias and are second- or third-line agents for these disorders. The effects of guanosine metabolites as anticancer agents are modest. They work through their antimetabolite action, resulting in incorporation into DNA, with subsequent prevention of cell proliferation (54). Our results suggest that these same metabolites inhibit PTHrP production, possibly by direct interaction with the PTHrP promoter. It is interesting to note that the only antimetabolites that inhibited PTHrP expression were those related to guanosine. These guanosine analogs also showed considerable specificity for the PTHrP promoter, with no evidence of effects on other promoters that we examined, including the PTH promoter. An interesting issue will be whether the dose required for these agents to inhibit metastasis to bone is less than that for an antitumor effect. Our preliminary data using these models suggest that a lower dose is indeed required, and if this is the case, the toxicity profile for guanosine analogs would be very favorable for their use as antiosteolytic agents.

Corticosteroids have had a checkered history as cytotoxic agents in the treatment of patients with cancers. They are clearly useful in patients with lymphomas and in the treatment of acute leukemia $(55,56)$. Dex-
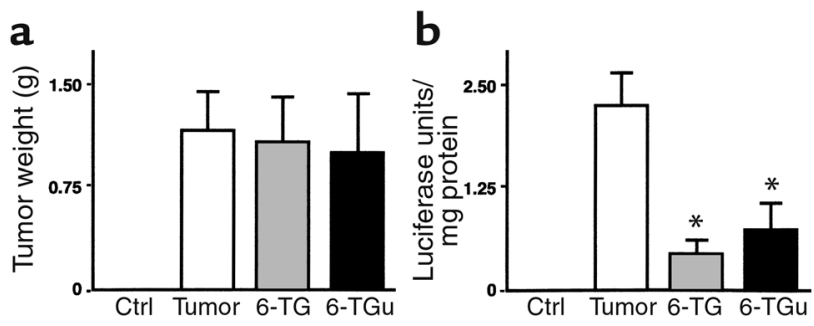

\section{Figure 10}

(a) Effect of 6-thioguanine and 6-thioguanosine on tumor weight. Tumor weight was assessed after intramuscular injection of MDAMB-231 tumor cells on day 0 . Treatment with 6-thioguanine or 6-thioguanosine $(1.0 \mathrm{mg} / \mathrm{kg} /$ day subcutaneously) was begun on the following day and and treated daily for the duration of the experiment. (b) Effect of 6-thioguanine and 6-thioguanosine on tumor burden in bone. Tumor burden in bone was assessed following intracardiac injection of MDA-MB-231 F9AD/Luc tumor cells on day 0 . Treatment with 6-thioguanine or 6-thioguanosine ( $1.0 \mathrm{mg} / \mathrm{kg} /$ day subcutaneously) was begun on the following day and treated daily for the duration of the experiment. Values represent means \pm SEM ( $n=5$ per group). Ctrl, control; 6-TG, 6-thioguanine; 6-TGu, 6-thioguanosine. ${ }^{*} P<0.05$. 

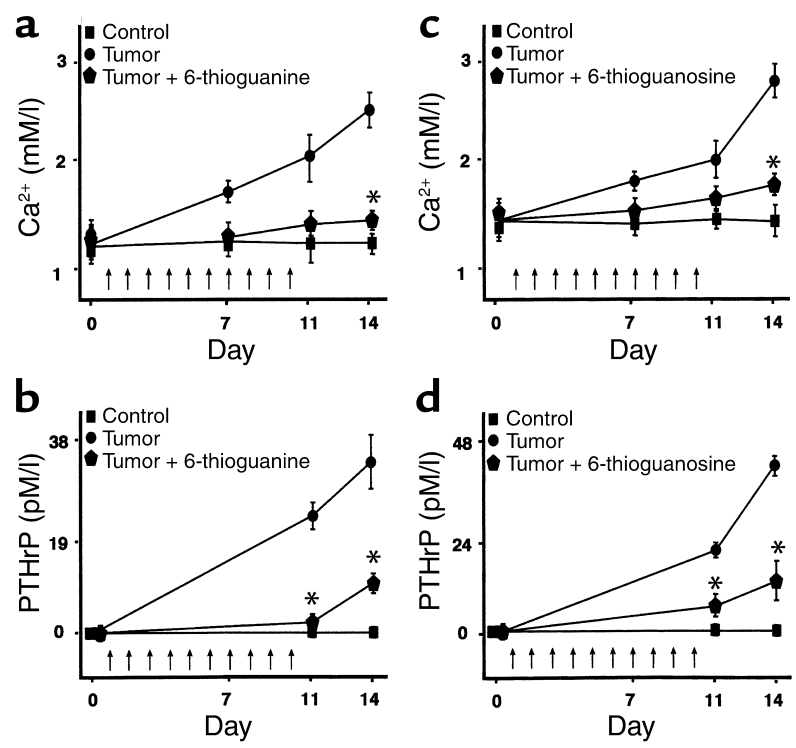

Figure 11

(a) Effect of 6-thioguanine on blood ionized-calcium concentrations in male athymic nude mice bearing RWGT2 cells. Treatment with 6-thioguanine was begun on the following day. Vertical arrows indicate the days of treatment. We administered 6-thioguanine (10 $\mathrm{mg} / \mathrm{kg}$ /day subcutaneously) for the first 10 days of the experiment. Final blood samples were obtained 1-2 hours after 6-thioguanine was given. (b) Effect of 6-thioguanine on serum PTHrP concentrations in male athymic nude mice bearing RWGT2 cells. Treatment with 6-thioguanine was begun on the following day. Vertical arrows indicate the days of treatment. We administered 6-thioguanine (10 $\mathrm{mg} / \mathrm{kg} /$ day subcutaneously) for the first 10 days of the experiment. Final blood samples were obtained 1-2 hours after 6-thioguanine was given. (c) Effect of 6-thioguanosine on blood ionized-calcium concentrations in male athymic nude mice bearing RWGT2 cells. Treatment with 6-thioguanosine was begun on the following day. Vertical arrows indicate the days of treatment. We administered 6-thioguanosine (10 mg/ $\mathrm{kg} /$ day subcutaneously) for the first 10 days of the experiment. Final blood samples were obtained 1-2 hours after 6-thioguanosine was given. (d) Effect of 6-thioguanosine on serum PTHrP concentrations in male athymic nude mice bearing RWGT2 cells. Treatment with 6-thioguanosine was begun on the following day. Vertical arrows indicate the days of treatment. We administered 6-thioguanosine $(10 \mathrm{mg} / \mathrm{kg} /$ day subcutaneously) for the first 10 days of the experiment. Final blood samples were obtained 1-2 hours after 6-thioguanosine was given. Values in all panels represent means $\pm \operatorname{SEM}(n=5$ per group $) .{ }^{*} P<0.05$.

amethasone has been shown to effectively decrease PTHrP transcriptional activity and expression of PTHrP protein (57). Corticosteroids also hold an important place in the initial treatment of patients with myeloma, having a well-demonstrated cytotoxic effect (58). However, their place in the treatment of patients with solid tumors is difficult to ascertain. They also have a varied history in their use as agents in the treatment of hypercalcemia (59). Our data suggest that when used in very large, suprapharmacologic doses, as compared with doses used as treatments in the past, corticosteroids do in fact inhibit osteolysis caused by metastatic human breast cancer when the human breast-cancer cells are inoculated directly into the left ventricle of mice (22). This effect is associated with impairment of PTHrP expression.

There is a great need to identify new interventions designed to specifically target clinical syndromes of PTHrP excess. The guanosine metabolites compared favorably with the bisphosphonates in the treatment of metastatic osteolysis in this model. The bisphosphonates also cause beneficial effects both on tumor burden and on osteolysis, as we have shown with the guanosine metabolites (14). However, the mode of action of bisphosphonates is entirely different that of guanosine metabolites. The bisphosphonates exert their effects by causing inhibition of osteoclast activity. It remains to be seen whether bisphosphonates will have synergistic effects with the guanosine metabolites.
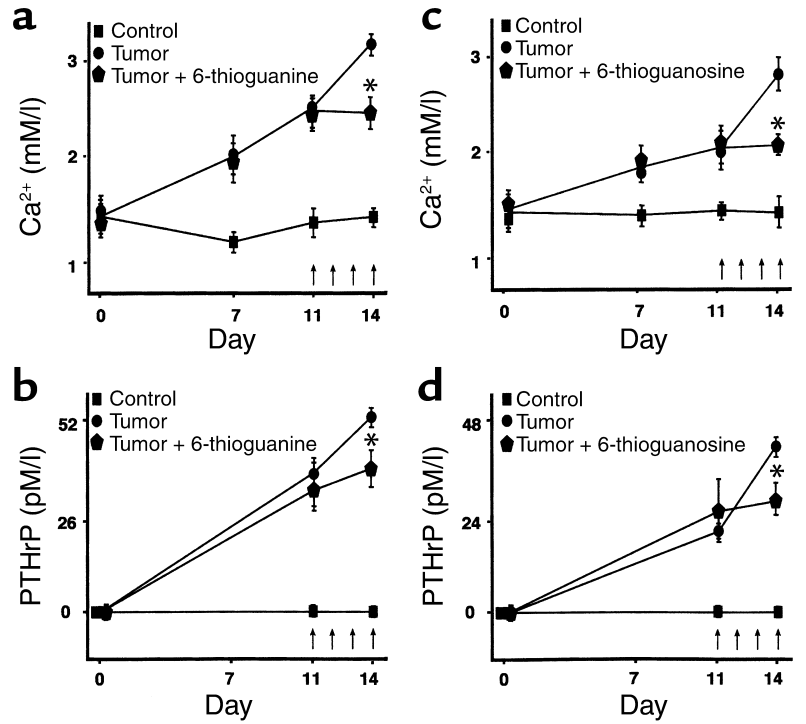

Figure 12

(a) Effect of 6-thioguanine on blood ionized-calcium concentrations in male athymic nude mice bearing RWGT 2 cells. Treatment with 6-thioguanine (10 mg/ $\mathrm{kg} /$ day subcutaneously) was begun on day 11 , after hypercalcemia became evident. Vertical arrows indicate the days of treatment. Final blood samples were obtained 1-2 hours after the fourth dose of 6-thioguanine was given. (b) Effect of 6-thioguanine on serum PTHrP concentrations in male athymic nude mice bearing RWGT2 cells. Treatment with 6-thioguanine (10 $\mathrm{mg} / \mathrm{kg} /$ day subcutaneously) was begun on day 11 , after hypercalcemia became evident. Vertical arrows indicate the days of treatment. Final blood samples were obtained 1-2 hours after the fourth dose of 6-thioguanine was given. (c) Effect of 6-thioguanosine on blood ionized-calcium concentrations in male athymic nude mice bearing RWGT2 cells. Treatment with 6-thioguanosine (10 mg/kg/day subcutaneously) was begun on day 11 , after hypercalcemia became evident. Vertical arrows indicate the days of treatment. Final blood samples were obtained 1-2 hours after the fourth dose of 6-thioguanosine was given. (d) Effect of 6-thioguanosine on serum PTHrP concentrations in male athymic nude mice bearing RWGT2 cells. Treatment with 6-thioguanosine (10 $\mathrm{mg} / \mathrm{kg} /$ day subcutaneously) was begun on day 11 , after hypercalcemia became evident. Vertical arrows indicate the days of treatment. Final blood samples were obtained 1-2 hours after the fourth dose of 6-thioguanosine was given. Values in all panels represent means $\pm \operatorname{SEM}(n=5$ per group $) .{ }^{*} P<0.05$. 
There is considerable potential for the use of guanosine metabolites in patients with bone disease caused by breast cancer. It seems likely that guanosine metabolites may find a place either alone or in combination with other agents such as the bisphosphonates. Our data support the notion that after studies to determine a safe dose have been performed, a randomized clinical trial is required to determine the effects of guanosine metabolites in the treatment of patients with metastatic breast cancer when PTHrP is likely to be responsible for the osteolysis.

In conclusion, we have described a promising new approach to the treatment of patients with breast cancer metastatic to bone and HHM caused by PTHrP excess. Our data is consistent with the "vicious-cycle" hypothesis $(60,61)$ - namely, that PTHrP production by breast-cancer cells in the bone microenvironment leads to bone resorption, which in turn leads to release of local growth factors from bone that are responsible for further aggressive behavior of the tumor cell and PTHrP expression. The guanosine metabolites have the capability of limiting PTHrP expression, thereby inhibiting this vicious cycle and decreasing the growth of the tumor cells in the bone microenvironment by this indirect mechanism.

\section{Acknowledgments}

We thank Marcia Castano, Suzanne Taylor, Gloria Chapa, Javier Esparza, Diane Horn, Mei Qiao, Monica Jalomo, and Mark Dallas for their technical assistance. This study was supported in part by Grant P01CA40035 from the National Cancer Institute.

1. Guise, T.A., et al. 1996. Evidence for a causal role of parathyroid hormone-related protein in the pathogenesis of human breast cancer-mediated osteolysis. J. Clin. Invest. 98:1544-1549.

2. Guise, T.A., Yoneda, T., Yates, A.J., and Mundy, G.R. 1993. The combined effect of tumor-produced parathyroid hormone-related peptide and transforming growth factor- $\alpha$ enhance hypercalcemia in vivo and bone resorption in vitro. J. Clin. Endocrinol. Metab. 77:40-45.

3. Kukreja, S.C., et al. 1988. Antibodies to parathyroid hormone-related protein lower serum calcium in athymic mouse models of malignancyassociated hypercalcemia due to human tumors. J. Clin. Invest. 82:1798-1802.

4. Houston, S.J., and Rubens, R.D. 1994. Metastatic bone pain. Pain Rev. 1:138-152.

5. Rubens, R.D., and Mundy, G.R. 2000. Cancer and the skeleton. Martin Dunitz. London, United Kingdom. 286 pp.

6. Hortobagyi, G.N., et al. 1996. Efficacy of pamidronate in reducing skeletal complications in patients with breast cancer and lytic bone metastases. New Engl. J. Med. 335:1785-1791.

7. Lipton, A., et al. 2000. Pamidronate prevents skeletal complications and is effective palliative treatment in women with breast carcinoma and osteolytic bone metastases: long term follow-up of two randomized, placebo-controlled trials. Cancer 88:1082-1090.

8. Diel, I.J., et al. 1998. Reduction in new metastases in breast cancer with adjuvant clodronate treatment. N. Engl. J. Med. 339:357-363.

9. Sasaki, A., et al. 1995. Bisphosphonate risedronate reduces metastatic human breast cancer burden in bone in nude mice. Cancer Res. 55:3551-3557.

10. Mundy, G.R., and Yoneda, T. 1998. Bisphosphonates may be anti-cancer drugs. New Engl. J. Med. 339:398-400.

11. Yoneda, T., et al. 2000. Actions of bisphosphonate on bone metastasis in animal models of breast carcinoma. Cancer. 88:2979-2988.

12. Sasaki, A., et al. 1995. Biphosphonate risedronate reduces metastatic human breast cancer burden in bone in nude mice. Cancer Res. 55:3551-3557.

13. Cailleau, R., Yong, R., Olive, M., and Reeves, W.J. 1974. Breast tumor cell lines from pleural effusions. J. Natl. Cancer Inst. 53:661-674.
14. Yoneda, T., et al. 1999. Use of bisphosphonates for the treatment of bone metastasis in experimental animal models. Cancer Treat. Rev. 25:293-299.

15. Ghosh-Choudhury, N., et al. 1996. Immortalized murine osteoblasts derived from BMP-2-T-antigen expressing transgenic mice. Endocrinology. 137:331-339.

16. Chong, M.T., and Lippman, M. 1980. Purification of estrogen receptors from MCF-7 human breast cancer cells. Cancer Res. 40:3172-3176.

17. Engel, L.W., et al. 1978. Establishment and characterization of three new continuous cell lines derived from human breast carcinomas. Cancer Res. 38:3352-3364.

18. Chomczynski, P., and Sacchi, N. 1987. Single-step method of RNA isolation by acid guanidinium thiocyanate-phenol-chloroform extraction. Anal. Biochem. 162:156-159.

19. Bouaboula, M., et al. 1992. Standardization of mRNA titration using a polymerase chain reaction method involving co-amplification with a multispecific internal control. J. Biol. Chem. 267:21830-21838.

20. Van Bezooijen, R.L., Farih-Sips, H.C.M., Papapoulos, S.E., and Lowik, C.W. 1998. IL- $1 \alpha$, IL-1 $\beta$, IL-6, and TNF- $\alpha$ steady-state mRNA levels analyzed by reverse transcription-competitive PCR in bone marrow of gonadectomized mice. J. Bone Miner. Res. 13:185-194.

21. Van der Pluijm, G., et al. 2001. Monitoring metastatic behavior of human tumor cells in mice with species-specific polymerase chain reaction: elevated expression of angiogenesis and bone resorption stimulators by breast cancer in bone metastases. J. Bone Miner. Res. 16:1077-1091.

22. Uy, H.L., et al. 1997. Dexamethasone inhibits bone metastasis caused by human breast cancer via several mechanisms. J. Bone Min. Res. 12(Suppl.):S181. (Abstr.)

23. Powell, G.J., et al. 1991. Localization of parathyroid hormone-related protein in breast cancer metastases: increased incidence in bone compared with other sites. Cancer Res. 51:3059-3061.

24. Vargas, S.J., et al. 1992. Localization of parathyroid hormone-related protein mRNA expression and metastatic lesions by in situ hybridization. J. Bone Miner. Res. 7:971-979.

25. Bouizar, Z., Spyratos, F., Deytieux, S., de Vernejoul, C.M., and Jullienne, A. 1993. Polymerase chain reaction analysis of parathyroid hormonerelated protein gene expression in breast cancer patients and occurrence of bone metastases. Cancer Res. 53:5076-5078.

26. Bundred, N.J., et al. 1991. Parathyroid hormone-related protein and hypercalcemia in breast cancer. Br. Med. J. 303:1506-1509.

27. Kohno, N., et al. 1994. The expression of parathyroid hormone-related protein in human breast cancer with skeletal metastases. Surg. Today. 24:215-220.

28. Aaron, A.D. 1994. The management of cancer metastatic bone. J. Am. Med. Assoc. 272:1206-1209.

29. Ackery, D., and Yardley, J. 1993. Radionuclide-targeted therapy for the management of metastatic bone pain [erratum 1993, 20:551]. Semin. Oncol. 20:27-31.

30. Robinson, R.G., Preston, D.F., Schiefelbein, M., and Baxter, K.G. 1995. Strontium 89 therapy for the palliation of pain due to osseous metastases. J. Am. Med. Assoc. 274:420-424.

31. Delmas, P.D. 1996. Bisphosphonates in the treatment of bone diseases. N. Engl. J. Med. 335:1836-1837.

32. Delmas, P.D., et al. 1997. Bisphosphonate risedronate prevents bone loss in women with artificial menopause due to chemotherapy of breast cancer: a double blind placebo-controlled trial. J. Clin. Oncol. 15:955-962.

33. Roberts, M.M., and Stewart, A.F. 1999. Primer on the metabolic bone diseases and disorders of mineral metabolism. Lippincott Williams \& Wilkins. Philadelphia, Pennsylvania, USA. 203-207.

34. Burtis, W.J., et al. 1990. Immunochemical characterization of circulating parathyroid hormone-related protein in patients with humoral hypercalcemia of cancer. N. Engl. J. Med. 322:1106-1112.

35. Pandian, M.R., Morgan, C.H., Carlton, E., and Segre, G.V. 1992. Modified immunoradiometric assay of parathyroid hormone-related protein: clinical application in the differential diagnosis of hypercalcemia. Clin. Chem. 38:282-288.

36. Uy, H.L., et al. 1995. Effects of parathyroid hormone (PTH)-related protein and PTH on osteoclasts and osteoclast precursors in vivo. Endocrinology. 136:3207-3212.

37. De la Mata, J., et al. 1995. IL-6 enhances hypercalcemia and bone resorption mediated by PTHrP in vivo. J. Clin. Invest. 95:2846-2852.

38. Pizurki, L., Rizzoli, R., Caverzasio, J., and Bonjour, J.P. 1990. Effect of transforming growth factor $\alpha$ and parathyroid hormone-related protein on phosphate transport in renal cells. Am. J. Physiol. 259:F929-F935.

39. Pzurki, L., Rizzoli, R., Caverzasio, J., and Bonjour, J.P. 1991. Stimulation by parathyroid hormone-related protein and transforming growth factor $\alpha$ of phosphate transport in osteoblast-like cells. J. Bone Miner. Res. 6:1235-1241.

40. Uy, H.L., et al. 1997. Tumor necrosis factor enhances parathyroid hormone-related protein (PTH-rP)-induced hypercalcemia and bone resorption without inhibiting bone formation in vivo. Cancer Res. 57:3194-3199.

41. Allinson, E.T., and Drucker, D.J. 1992. Parathyroid hormone-like pep- 
tide shares features with members of early response gene family: rapid inductions by serum growth factors and cyclohexamide. Cancer Res. 52:3103-3109.

42. Sebag, M., Henderson, J., Goltzman, D., and Kremer, R. 1994. Regulation of parathyroid hormone-related peptide production in normal human mammary epithelia cells in vitro. Am. J. Physiol. 267:C723-C730.

43. Burton, P.B., Moniz, C., and Knight, D.E. 1990. Parathyroid hormonerelated peptide can function as an autocrine growth factor in human renal cell carcinoma. Biochem. Biophys. Res. Commun. 167:1134-1138.

44. Rizzoli, R., et al. 1994. Regulation of parathyroid hormone-related protein production in a human lung squamous cell carcinoma line. J. Endocrinol. 143:333-341.

45. Dublin, E.A., Barnes, D.M., Wang, D.Y., King, R.J., and Levison, D.A 1993. TGF alpha and TFG beta expression in mammary carcinoma. J. Pathol. 170:15-22

46. Herman, M.E., and Katzenellenbogen, B.S. 1994. Alterations in transforming growth factor-alpha and -beta production and cell responsiveness during the progression of MCF-7 human breast cancer cells to estrogen-autonomous growth. Cancer Res. 54:5867-5874.

47. Van Roosendall, C.E.P., et al. 1995. Transforming growth factor beta secretion from primary breast cancer fibroblasts. Mol. Cell Endocrinol. 111:1-6.

48. Zakalik, D., Diep, D., Hooks, M.A., Nissenson, R.A., and Strewler, G.J. 1992. Transforming growth factor $\beta$ increases stability of parathyroid hormone-related protein messenger RNA. J. Bone Miner. Res. 7(Suppl.):S118. (Abstr.)

49. Merryman, J.I., DeWille, J.W., Werkmeister, J.R., Capen, C.C., and Rosol, T.J. 1994. Effects of transforming growth factor- $\beta$ on parathyroid hormone-related protein production and ribonucleic acid expression by a squamous carcinoma cell line in vitro. Endocrinology. 134:2424-2430.

50. Kriyama, T., et al. 1993. Transforming growth factor $\beta$ stimulation of parathyroid hormone-related protein (PTHrP): a paracrine regulator [erratum 1993, 94:145]. Mol. Cell Endocrinol. 92:55-62.

51. Firek, A et al. 1994. TGF- $\beta$ stimulates PTH-rP release from human mammary cancer. Program of the $76^{\text {th }}$ Annual Meeting of The Endocrine Society. June 15-18. Anaheim, California. The Endocrine Society Press. Bethesda, Maryland, USA. p. 395. (Abstr.)

52. Mertelsmann, R., et al. 1981. Treatment of acute nonlymphocytic leukemia in adults: response to 2,2-anhydro-1-B-D-arabinofuranosyl-5fluorocytosine and thioguanine on the L-12 protocol. Cancer. 48:2136-2142.

53. Buchner, T., et al. 1982. Multicentre study on intensified remission induction therapy for acute myeloid leukemia. Lenk. Res. 6:827-831.

54. Nelson, J.A., Carpenter, J.W., Rose, L.M., and Adamson, D.J. 1975. Mechanisms of action of 6-thioguanine, 6-mercaptopurine, and 8-azaguanine. Cancer Res. 35:2872-2878.

55. Coleman, R.E. 1992. Glucocorticoids in cancer therapy. Biotherapy 4:37-44.

56. Gaynon, P.S., and Carrel, A.L. 1999. Glucocorticosteroid therapy in childhood acute lymphoblastic leukemia. Adv. Exp. Med. Biol. 457:593-605.

57. Southby, J., Murphy, L.M., Martin, T.J., and Gillespie, M. 1996. Cell-specific and regulator-induced promoter usage and messenger ribonucleic acid splicing for parathyroid hormone-related protein. Endocrinology. 137:1349-1357.

58. Snapper, I., and Kahn, A. 1971. Myelomatosis: fundamentals and clinical features. University Park Press. Baltimore, Maryland, USA. 380 pp.

59. Mundy, G.R., Wilkinson, R., and Heath, D.A. 1983. Comparative study of available medical therapy for hypercalcemia of malignancy. Am. J. Med. 74:421-432.

60. Guise, T.A. 1997. Parathyroid hormone-related protein and bone metastases. Cancer. 80:1572-1580.

61. Guise, T.A., and Mundy, G.R. 1998. Cancer and bone. Endocr. Rev. 19:1-54. 